\title{
Osteoblastic Differentiation of Amniotic Pluripotent Stem Cell
}

\section{A R T I C L E I N F O}

\section{Article Type}

Original research

\section{Authors}

Mahmoodinia Maymand M. ${ }^{1} M S c$ ? Noruzinia M.* $M D, M P H$

\section{How to cite this article} Mahmoodinia Maymand M, Noruzinia M. Osteoblastic Differentiation of Amniotic Pluripotent Stem Cell. Sarem Journal of Reproductive Medicine. 2017;1(1) $9-13$

\begin{abstract}
A B S T R A C T
Aims Amniotic fluid stem cells have lower ethical limitations than embryonic stem cells for the use in research and treatment. These cells show great self-renewal potential and can differentiate into the specialized cells of all three germ layers. The amniotic fluid stem cells display minimal risks of teratomas and very low immunogenicity. For these reasons, amniotic fluid appears as a promising alternative source for stem cell therapy. The objective of this study was to isolate the stem cells from amniotic fluid and differentiate them into the osteoblastic cells.

Materials \& Methods An amniotic fluid sample (about 10ml) was collected from a healthy donor in Sarem women's hospital (Tehran, Iran). After centrifugation, the cells were cultured in a DMEM medium supplemented with 20\% FBS. The cell clones were observed after two weeks and were passaged to an osteoblastic differentiation medium. Alizarin red staining and RTPCR for alkaline phosphatase and osteocalcin markers were used for confirmation of cellular differentiation.

Findings Stem cells were isolated from amniotic fluid. Phenotypically, these cells showed spindle-shaped morphology with a large nucleus. Following the induction of differentiation, they showed the expression of osteoblastic cells markers indicating their differentiation. The expression of those markers was confirmed by immunocytochemistry and RT-PCR.

Conclusion Amniotic stem cells have the ability to differentiate into the osteoblastic cells using an osteoblastic differentiation medium.
\end{abstract}

Keywords Fetal Stem Cells; Amniotic Fluid; Osteoblasts; Cell Differentiation
*Medical Genetics Department, Faculty of Medical Sciences, Tarbiat Modares University, Tehran, Iran ${ }^{1}$ Sarem Cell Research Center (SCRC), Sarem Women's Hospital, Tehran, Iran

\section{Correspondence}

Address: -

Phone: -

Fax: -

noruzinia@modares.ac.ir

\section{Article History}

Received: September 27, 2015

Accepted: January 12, 2016

ePublished: February 15, 2017

\section{I T A T I O N L I N K S}

[1] Amniotic fluid cells and human stem cell research: A new connection [2] Isolation of osteogenic progenitors from human amniotic fluid using a single step culture protocol [3] Isolation, differentiation and biochemical aspects of amniotic fluid stem cell [4] In vitro and in vivo study of human amniotic fluid-derived stem cell differentiation into myogenic lineage [5] Development of amniotic fluid-derived stem cell [6] Adult mesenchymal stem cells: Characterization, differentiation, and application in cell and gene therapy [7] Isolation of amniotic stem cell lines with potential for therapy [8] Versatile stem cells without the ethical baggage? [9] The amniotic fluid as a source of cells for fetal tissue engineering [10] Osteocyte-osteoclast morphological relationships and the putative role of osteocytes in bone remodeling [11] Tissue engineering craniofacial defects with adult stem cells? Are we ready yet? [12] Effects of implantation of bone marrow mesenchymal stem cells, disc distraction and combined therapy on reversing degeneration of the intervertebral disc [13] Epigenetic modifications in osteogenic differentiation and transformation [14] Osteoblast differentiation of human bone marrow cells under continuous and discontinuous treatment with dexamethasone [15] Craniofacial tissue engineering by stem cells [16] Mesenchymal stem cells: Cell biology and potential use in therapy [17] Adhesion to vitronectin and collagen I promotes osteogenic differentiation of human mesenchymal stem cells [18] Induced differentiation of adult human bone marrow derived mesenchymal stem cells in vitro toward osteoblasts [19] Modulation of osteogenesis in human mesenchymal stem cells by specific pulsed electromagnetic field stimulation [20] Discovery of osteoblast-associated genes using cDNA microarrays 


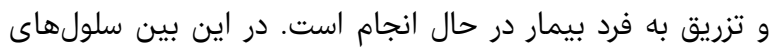

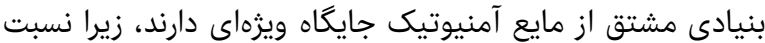

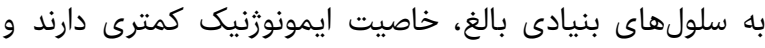

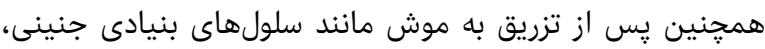

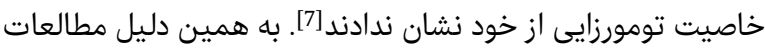

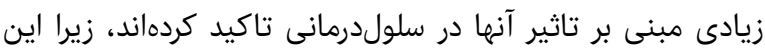

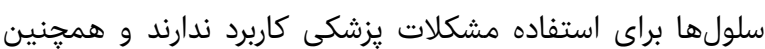

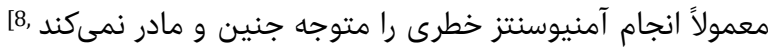

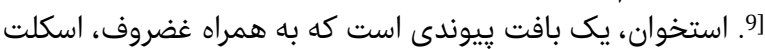

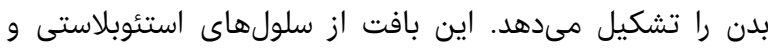

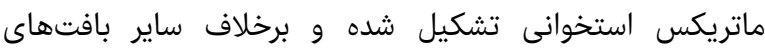

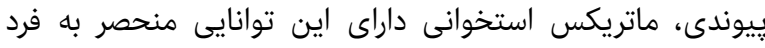

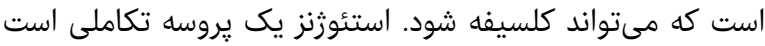

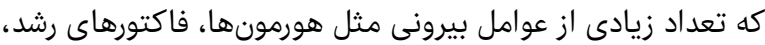

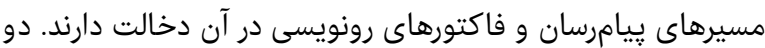

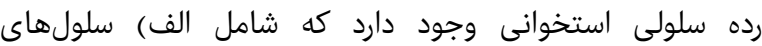

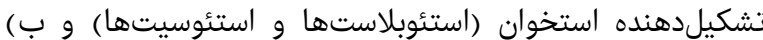

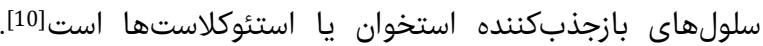

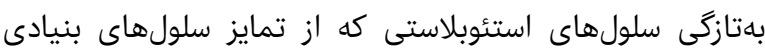

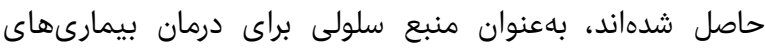

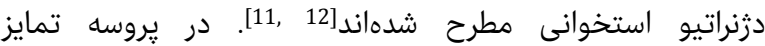

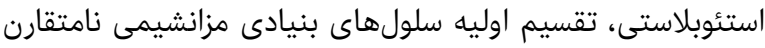

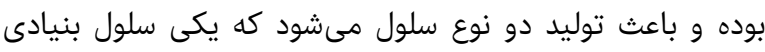

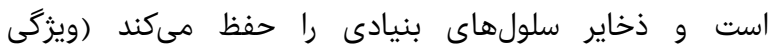

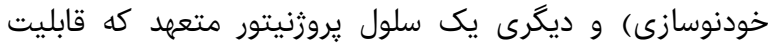
تبديل به رده استئوبلاستى را دارا است (Potency)

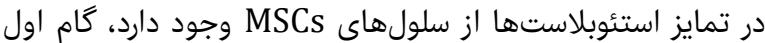

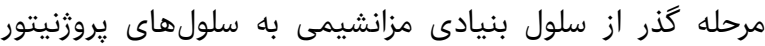

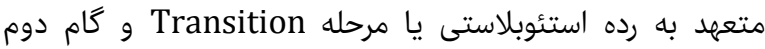

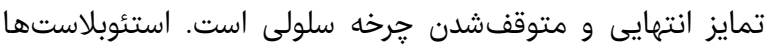

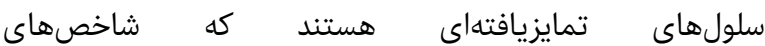
ALP ، Osteopontin،Osteocalcin

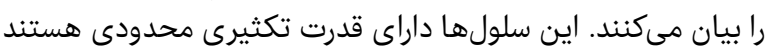

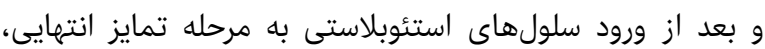

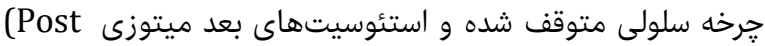
mitotic)

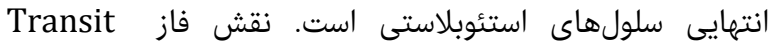

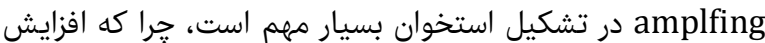

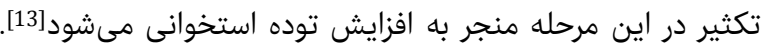

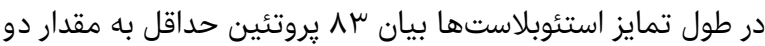

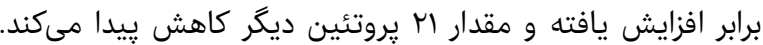

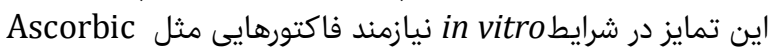
Dexametasone ،acid

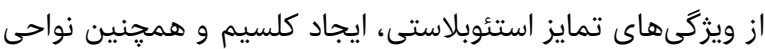

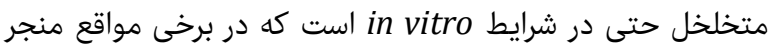

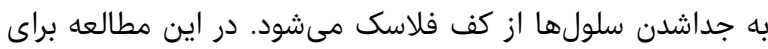

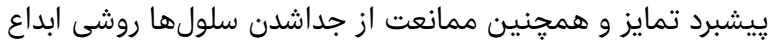

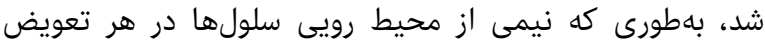

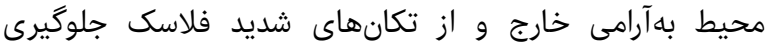

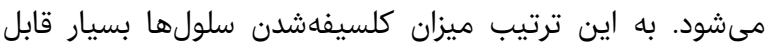

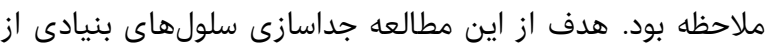
مايع آمنيوتيك و تمايز آنها به سلولهاى استئوبلاستى بود

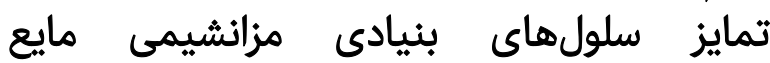 آمنيوتيك به سلولهاي استئوبلاستى}

جكيده

اهداف: سلولهاى بنيادى مايع آمنيوتيك در مقايسه با سلولهاى بنيادى

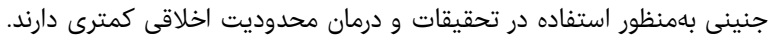

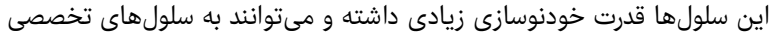

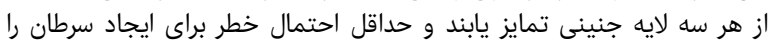

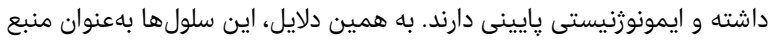

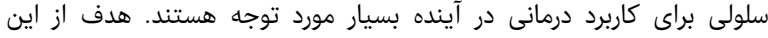

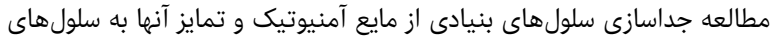
استئوبلاستى بود.

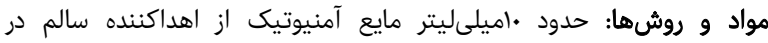

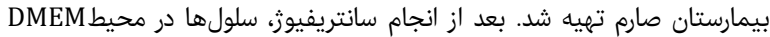

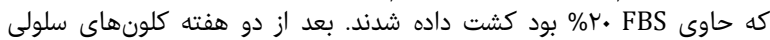

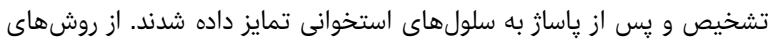

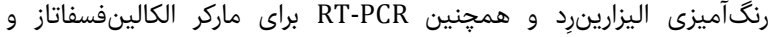

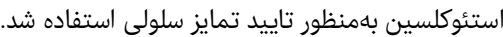

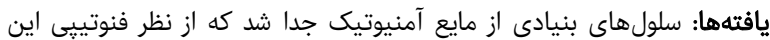

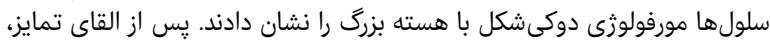

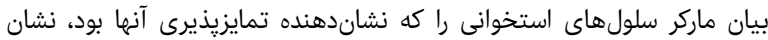
دادند. بيان اين ماركرها به وسيله تكنيك ايمونوسيتوانيتوشيمى و و RT-PCR تاييد

نتيجهيرى: سلولهاى بنيادى مايع آمنيوتيك با بهكارگيرى محيط تمايزى

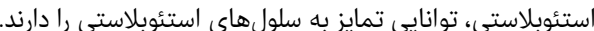

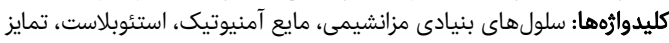

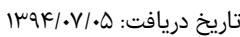

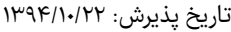
noruzinia@modares.ac.ir :تويسنده مسئول

مقلهـ

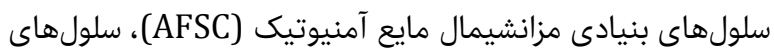

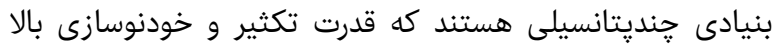

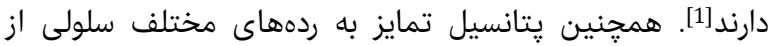

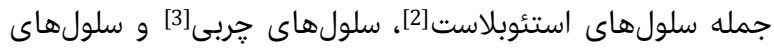

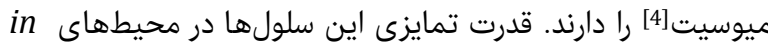
vivo و و همين و vitro vitro

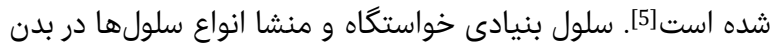
بوده و داراى دو ويزگى مهم يعنى يرتوانى (Pluripotency) و

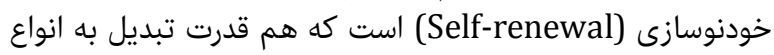
سلولها را دارد و هم مى تى تواند به سلولى تمايزنيافته مشابه خودش

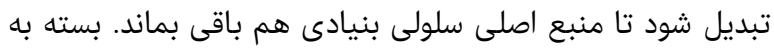

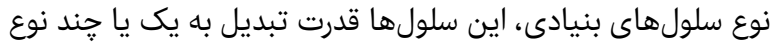

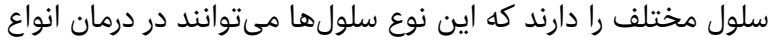

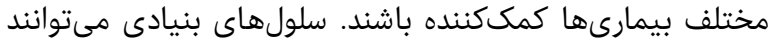

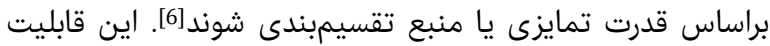

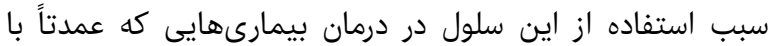

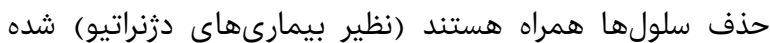
است، باطورى كه مطالعات وسيعى روى تامين تعداد كافى سلول 


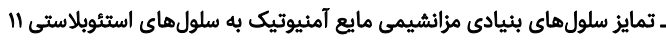

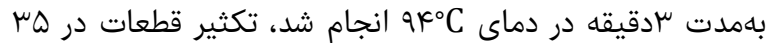
سيكل با دماهاى

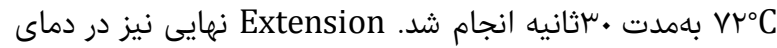

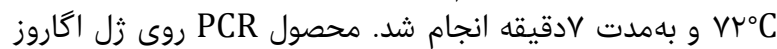

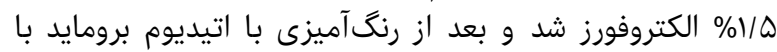

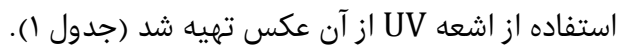

جدول () توالى يرايمرهاى استفادهشده در اين مطالعه

\begin{tabular}{|c|c|c|}
\hline اندازه محصول & توالى ('- & يرايمر \\
\hline $191 \mathrm{bp}$ & $\begin{array}{l}\text { GCA CCT GCC TTA CTA ACT C } \\
\text { AGA CAC CCA TCC CAT CTC }\end{array}$ & ALP F \\
\hline$r \Delta \cdot b p$ & $\begin{array}{l}\text { TCA CAC TCC TCG CCC TAT TGG } \\
\text { GAT GTG GTC AGC CAA CTC GTC A }\end{array}$ & $\begin{array}{l}\text { Osc F } \\
\text { Osc R }\end{array}$ \\
\hline
\end{tabular}

يافتهها

درصد Viability سلولها حدود •^\% بود. مشاهده سلولها با

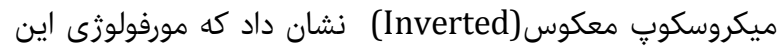
سلولها مشابه سلولهاى فيبروبلاستى بود (شكل ().
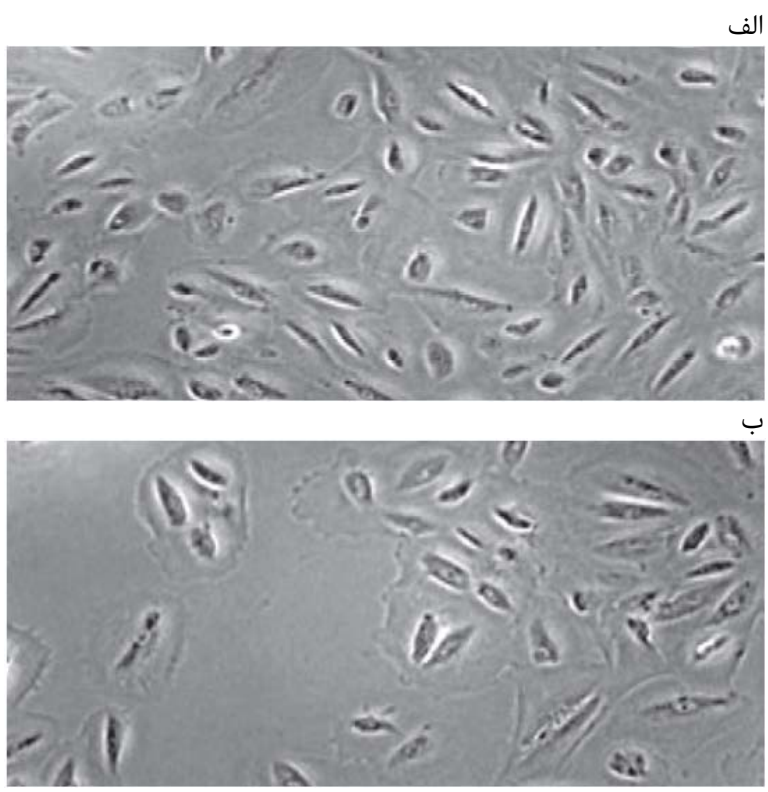

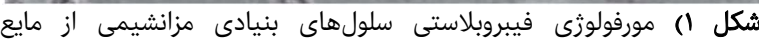
آمنيوتيك نتيجه رنكآميزى اليزارينرد

همجنين نتايج حاصل از فلوسايتومترى، نشاندهنده بيان

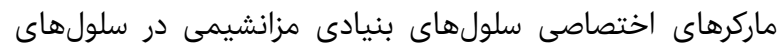

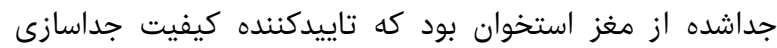

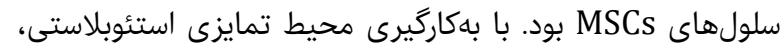

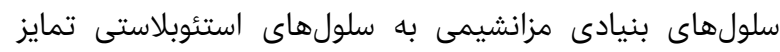

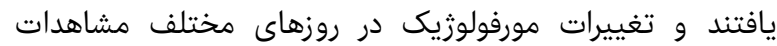

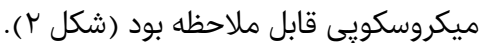

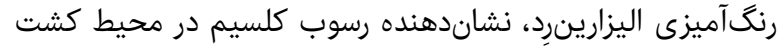

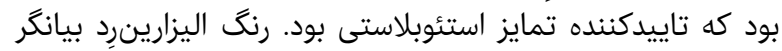

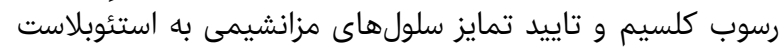
بود كه البته از سلولهاى بنيادى مزانشيمى تمايز سايزنيافته بودند و

مواد و روشها

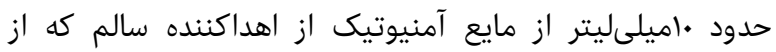

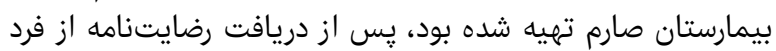

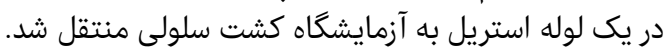

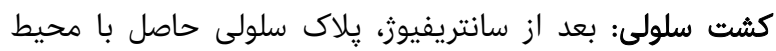

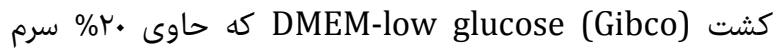
و و ينىسيلين - استريتومايسين (GBS (Gibco)

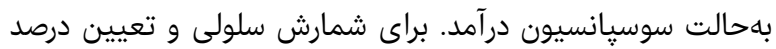

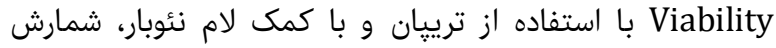

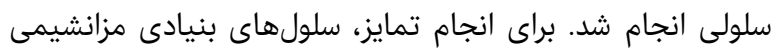

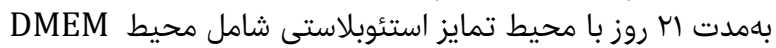

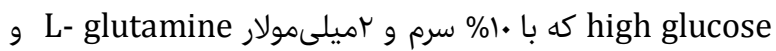

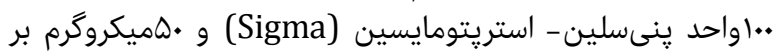

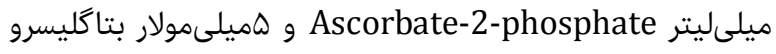

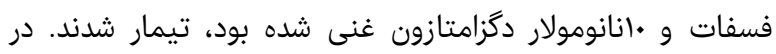

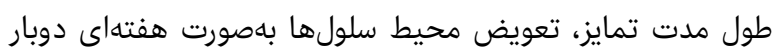

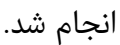

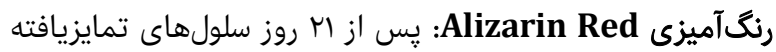

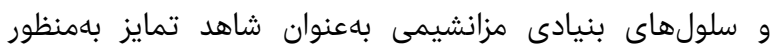

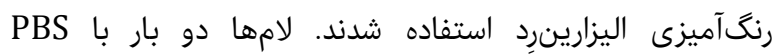

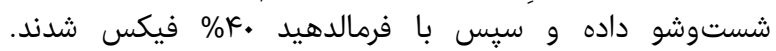

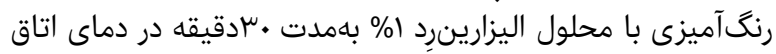

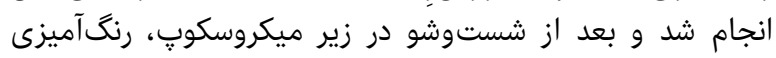

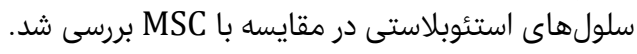

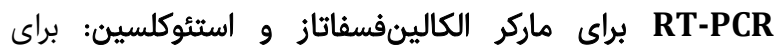
استخراج RNA از كيت Rima Zol (طيف آرا فرآيند) استفاده شداند.

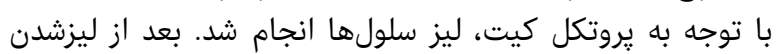

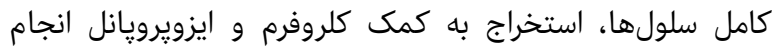

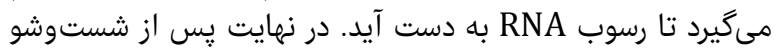

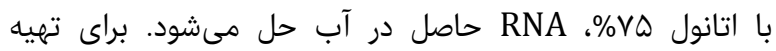

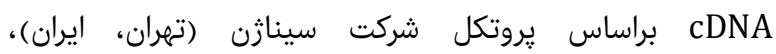
•اميكروليتر محلول RNA را در دماى شراى

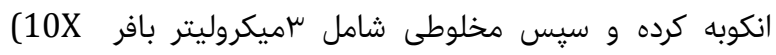

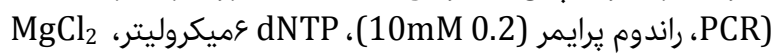
را و Reverse Transcriptase (25Mm) به آن اضافه كرديم. محلول حاصل را •ادقيقه در

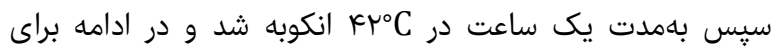

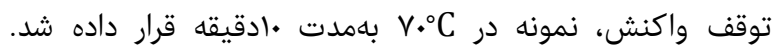

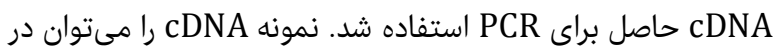

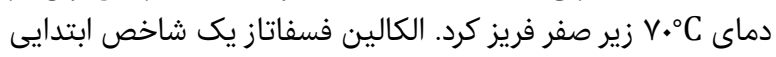

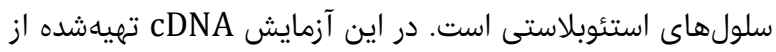

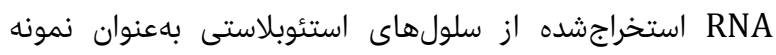

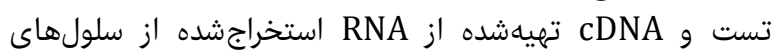

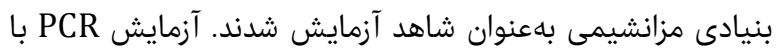

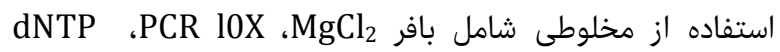

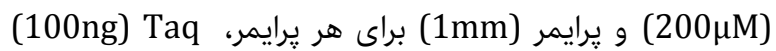

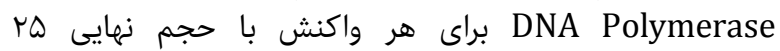
ميكروليتر در نظر گرفته شد. بعد از مرحله دناتوراسيون اوليه نه 


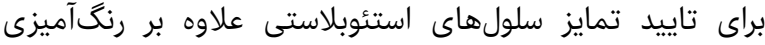

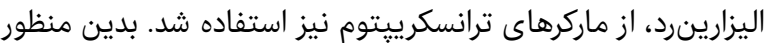

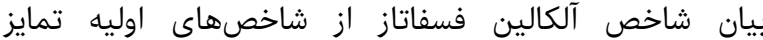

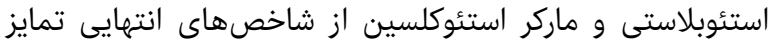

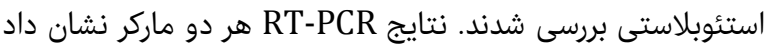

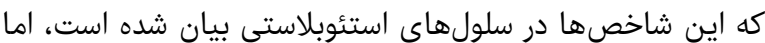

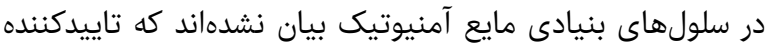
تمايز سلولهاى استئوبلاستى بود (شكلهاى مائ و ه هان.

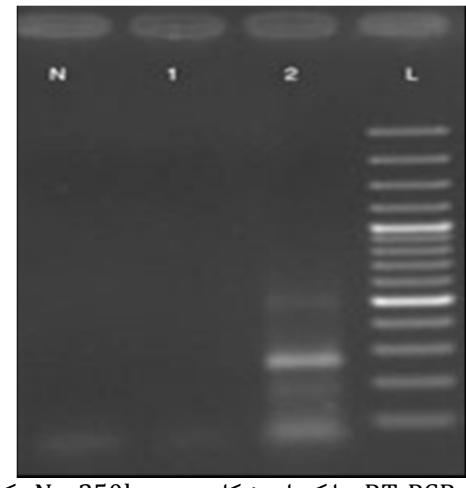

شكل \&) نتيجه RT-PCR ماركر استئوكلسين؛ 250bp (N) كنترل منفى، ا:

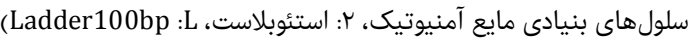

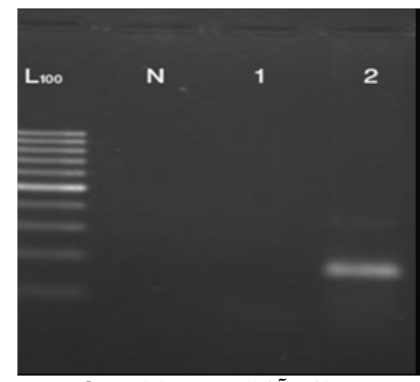

شكل ه) نتيجه RT-PCR ماركر آلكالين فسفاتاز؛ No1bp 161bp: كنترل منفى، ا:

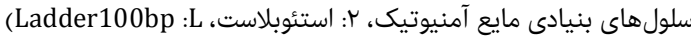

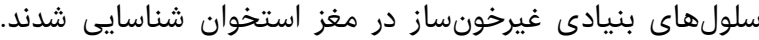

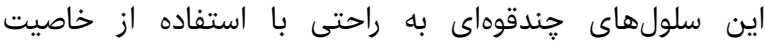

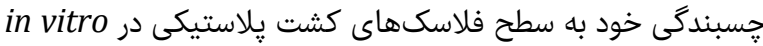

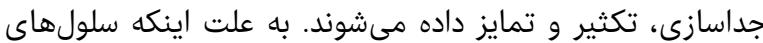

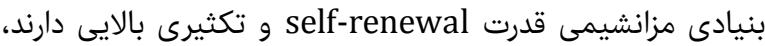

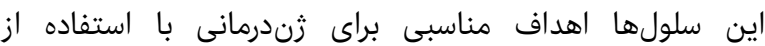

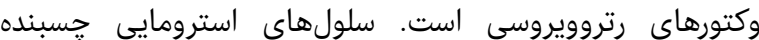

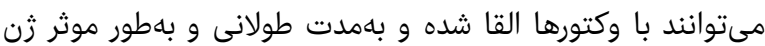

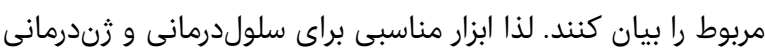

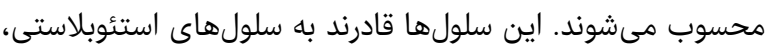

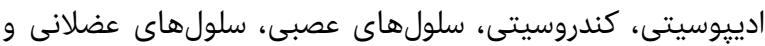

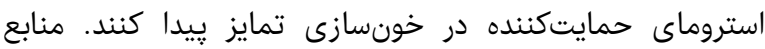

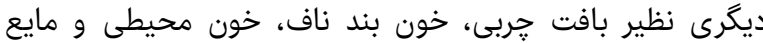

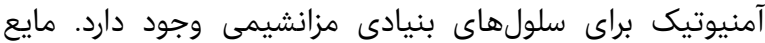

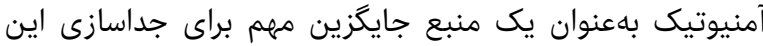

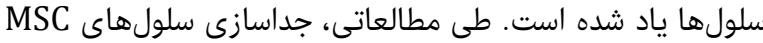
از مايع آمنيوتيك انسانى در سهماهه دوم باردارى [14] و همجنين هارين

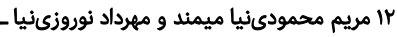

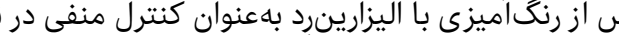
شد (شكل س).
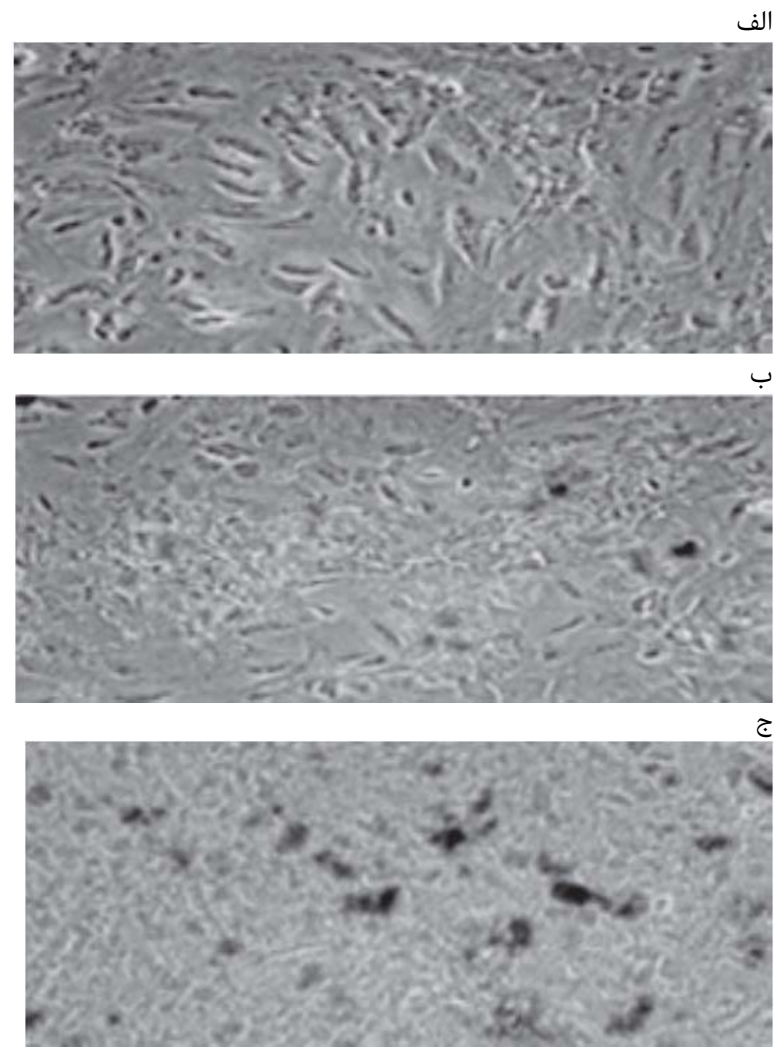

شكل r) سلولهاى بنيادى مزانشيمى در روزهاى مختلف تمايز (از بالا به پإيين بهترتيب) هفته اول، دوم و سوم تمايز
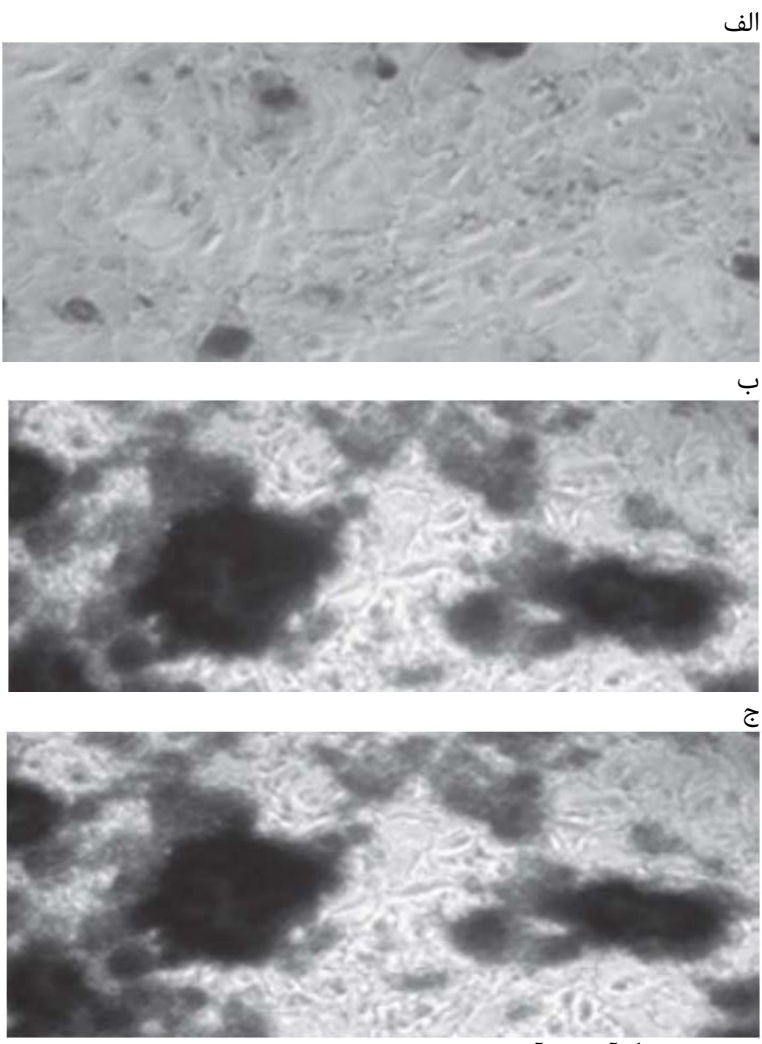

شكل \%) رنكَآميزى آليزارين رد براى تاييد تمايز استئوبلاستى، بخش الف

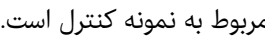

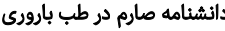


تمايز سلولهاى بنيادى مزانشيمى مايع آمنيوتيك به سلولهاى استئوبلاستى سار

2- Antonucci I, Iezzi I, Morizio E, Mastrangelo F, Pantalone A, Mattioli-Belmonte $\mathrm{M}$, et al. Isolation of osteogenic progenitors from human amniotic fluid using a single step culture protocol. BMC Biotechnol, 2009;9:9. 3- Cabral ACV, Ângelo PC, Leite HV, Pereira AK, Lopes APBM, Oliveira MB. Isolation, differentiation and biochemical aspects of amniotic fluid stem cell. Rev Assoc Med Bras. 2008;54(6):489-93.

4- Gekas J, Walther G, Skuk D, Bujold E, Harvey I, Bertrand OF. In vitro and in vivo study of human amniotic fluid-derived stem cell differentiation into myogenic lineage. Clin Exp Med. 10(1):1-6.

5- Zhang X, Chen X, Wang H, Liu S. Development of amniotic fluid-derived stem cell. Zhongguo Xiu Fu Chong Jian Wai Ke Za Zhi. 2008;22(7):864-8.

6- Baksh D, Song L, Tuan RS. Adult mesenchymal stem cells: Characterization, differentiation, and application in cell and gene therapy. J Cell Mol Med. 2004;8(3):301-16. 7-De Coppi P, Bartsch GJR, Siddiqui MM, Xu T, Santos CC, Perin $\mathrm{L}$, et al. Isolation of amniotic stem cell lines with potential for therapy. Nat Biotechnol. 2007;25(1):100-6. 8- Holden C. Versatile stem cells without the ethical baggage?. Science. 2007;315(5809):170.

9- Kaviani A, Perry TE, Dzakovic A, Jennings RW, Ziegler MM, Fauza DO, Et al. The amniotic fluid as a source of cells for fetal tissue engineering. J Pediatr Surg. 2001;36(11):1662-5.

10- Palumbo C, Ferretti M, Ardizzoni A, Zaffe D, Marotti G. Osteocyte-osteoclast morphological relationships and the putative role of osteocytes in bone remodeling. J Musculoskelet Neuronal Interact. 2001;1(4):327-32.

11- Zuk PA. Tissue engineering craniofacial defects with adult stem cells? Are we ready yet?. Pediatr Res. 2008;63(5):478-86.

12- Hee HT, Ismail HD, Lim CT, Goh JC, Wong HK. Effects of implantation of bone marrow mesenchymal stem cells, disc distraction and combined therapy on reversing degeneration of the intervertebral disc. J Bone Joint Surg Br. 2010;92(5):726-36.

13- Thomas D, Kansara M. Epigenetic modifications in osteogenic differentiation and transformation. J Cell Biochem. 2006;98(4):757-69.

14- Beloti, MM. Rosa AL. Osteoblast differentiation of human bone marrow cells under continuous and discontinuous treatment with dexamethasone. Braz Dent J. 2005;16(2):156-61.

15- Mao JJ, Giannobile WV, Helms JA, Hollister SJ, Krebsbach PH, Longaker MT, et al. Craniofacial tissue engineering by stem cells. J Dent Res. 2006;85(11):966-79. 16- Kassem M, Kristiansen M, Abdallah BM. Mesenchymal stem cells: Cell biology and potential use in therapy. Basic Clin Pharmacol Toxicol, 2004;95(5):209-14.

17- Salasznyk RM, Williams WA, Boskey A, Batorsky A, Plopper GE. Adhesion to vitronectin and collagen I promotes osteogenic differentiation of human mesenchymal stem cells. J Biomed Biotechnol. 2004;2004(1):24-34.

18- Liu XJ, Ren GH, Liao H, Yu L, Yuan L. Induced differentiation of adult human bone marrow derived mesenchymal stem cells in vitro toward osteoblasts. Di Yi Jun Yi Da Xue Xue Bao. 2004;24(4):408-11, 418.

19- Tsai MT, Li WJ, Tuan RS, Chang WH. Modulation of osteogenesis in human mesenchymal stem cells by specific pulsed electromagnetic field stimulation. J Orthop Res. 2009;27(9):1169-74.

20- Raouf A. Seth A. Discovery of osteoblast-associated genes using cDNA microarrays. Bone. 2002;30(3):463-71.

از مايع آمنيوتيك موش C57BL/6 صورت كرفته است. تمايز

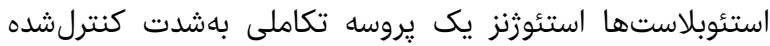

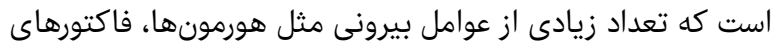

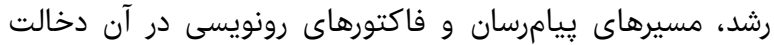

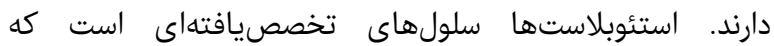

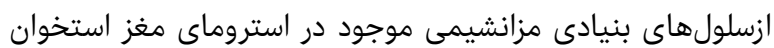

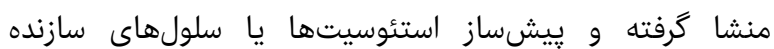

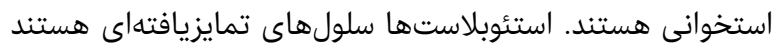

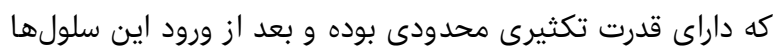

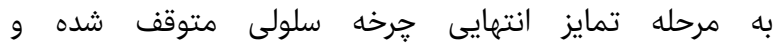

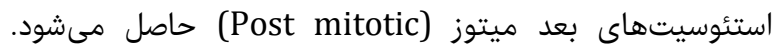

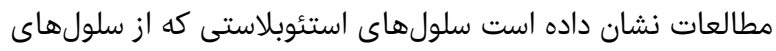

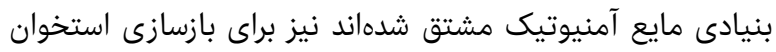

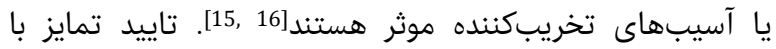

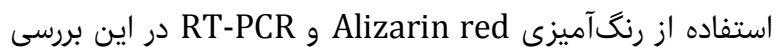

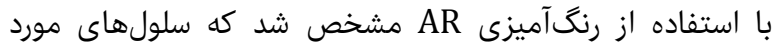

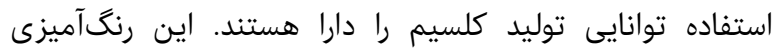

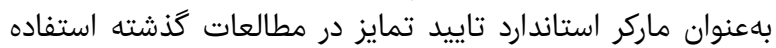

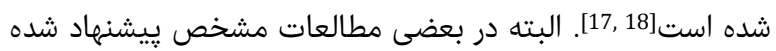

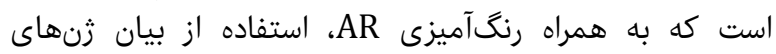

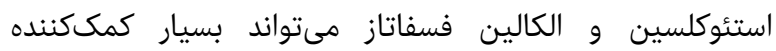

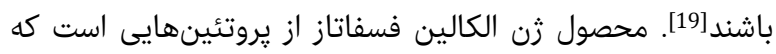

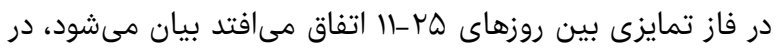

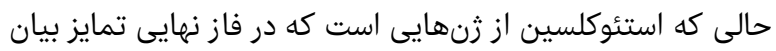

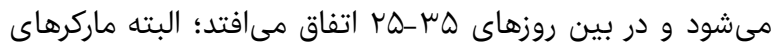

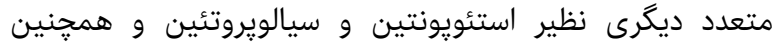

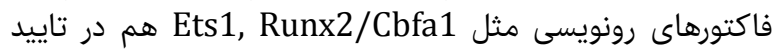

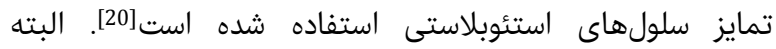

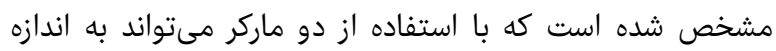

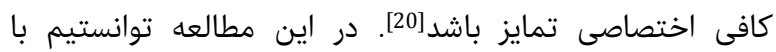

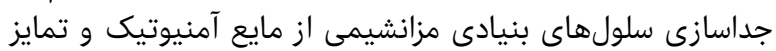

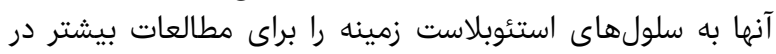

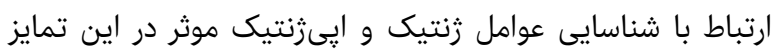

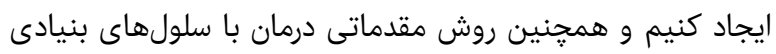

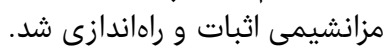

نتيجه نيرى سلولهاى بنيادى مايع آمنيوتيك با بهكاركيرى محيط تمايزى

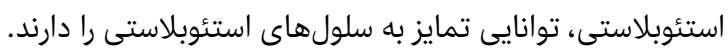
تشكر و قدردانى: موردى از سوى نويسندكان ذكر نشده است.

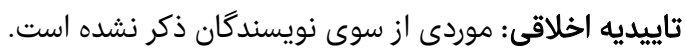
تعارض منافع: موردى وجود نداشته است.

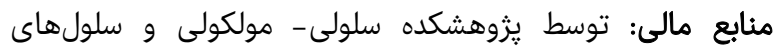

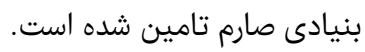

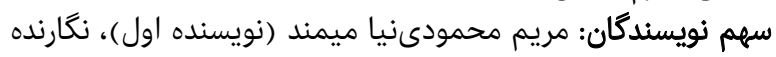

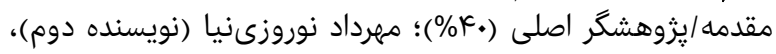

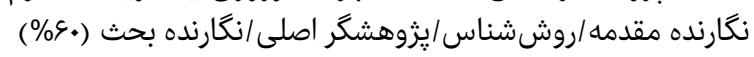

\section{منابع}

1- Prusa, AR, Hengstschlager M. Amniotic fluid cells and human stem cell research: A new connection. Med Sci Monit. 2002;8(11):RA253-7. 